Article

\title{
Numerical Study of the Effects of the Jet Fan Speed, Heat Release Rate and Aspect Ratio on Smoke Movement in Tunnel Fires
}

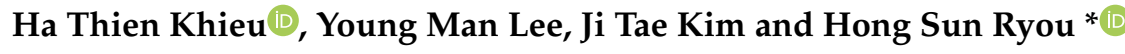 \\ School of Mechanical Engineering, Chung-Ang University, 84, Heukseok-ro, Dongjak-gu, Seoul 06974, Korea; \\ hathienkhieu@gmail.com (H.T.K.); ymlee@alllitelife.com (Y.M.L.); sdd322@naver.com (J.T.K.) \\ * Correspondence: cfdmec@cau.ac.kr; Tel.: +82-2-820-5280
}

Received: 4 February 2020; Accepted: 3 March 2020; Published: 5 March 2020

check for updates

\begin{abstract}
In this study, the effects of the jet fan speed, heat release rate and aspect ratio on smoke movement in tunnel fires have been investigated. The jet fan speed was changed from $6.25(25 \%)$ to $12.5 \mathrm{~m} / \mathrm{s}(50 \%), 18.75 \mathrm{~m} / \mathrm{s}(75 \%)$, and $25 \mathrm{~m} / \mathrm{s}(100 \%)$. The heat release rate was set up from 3.9 to $6 \mathrm{MW}$ and $16 \mathrm{MW}$, the aspect ratio was changed from 0.6 to 1 and 1.5, respectively. The lower the jet fan speed is, the longer the smoke back-layering length is. With a higher velocity, the smoke tends to move out of the tunnel quickly; however, smoke stratification also occurs, and this reduces visibility. This could make it difficult for people to evacuate. With a higher heat release rate, the smoke tends to move far away from the fires quickly when compared with other cases. Additionally, the higher the heat release is, the longer the smoke back-layering is. Finally, with a higher aspect ratio, the smoke back layering length in the tunnel is also longer. The smoke layer thickness is also larger than in other cases. The correlation of velocity, heat release rate and aspect ratio has been investigated to avoid the smoke back layer length in tunnel fires.
\end{abstract}

Keywords: tunnel fires; jet fan speed; heat release rate; aspect ratio; smoke movement; visibility; smoke layer thickness; smoke stratification

\section{Introduction}

Recently, there have been many tunnels under construction worldwide. A tunnel is an underground passageway commonly used in transportation, and studying fires in tunnels is very critical for human safety. When a fire occurs, smoke and toxic gases will be accumulated in the tunnel due to the nature of a tunnel structure. Two parts of typical smoke are $\mathrm{CO}_{2}$ and $\mathrm{CO}$, which are poisonous to humans. As smoke spreads across the tunnel, the smoke prohibits the evacuation of occupants and prevents firefighters from extinguishing the fire.

Many fire accidents have occurred in tunnels. These typically cause significant damage in both human and economic terms, causing many people to be killed and injured and many facilities destroyed; for these reasons, investigating tunnel fires is very important.

In order to prevent the smoke from spreading through an entire tunnel, mechanical ventilation systems are used to transport smoke from the tunnel to the outside. A jet fan is one of the main methods for ventilation in a tunnel; a jet fan can quickly move smoke from vehicles and fires outside of the tunnel. Correspondingly, investigating the jet fan speed on smoke movement in tunnels is necessary for decreasing human casualties.

João Carlos Viegas (2009) [1] investigated the interaction between a fire ceiling jet and the flow driven by the jet fan. In that paper, the use of impulse ventilation for smoke control in underground car parks was performed by using Computational Fluid Dynamics (CFD) simulations. M.G.L.C et al. 
(2010) [2] performed modeling and simulation of a jet fan for controlling airflow in large enclosures. A relatively simple CFD model of the free jet fan was proposed and validated. Moreover, the different series modes of jet fans in a longitudinal tunnel ventilation system were investigated by Guihong Pei and Jie Pan (2014) [3]. When most operational fans are located near the tunnel entrance, it is more conducive to increase the velocity and pressure inside the tunnel. Beyer $\mathrm{M}$ et al. (2016) [4] has considered the evaluation of the jet fan performance in tunnels. In a tunnel, due to the lack of space, the jet fan is usually installed close to the wall. However, this increases the wall shear stress around the jet, and thus, the effectiveness is significantly reduced.

An experimental study of the effect of the aspect ratio on the critical velocity in longitudinal ventilation tunnel fires was studied by Ryou et al. (2003) [5]. In that study, the aspect ratios of the tunnel were changed from $0.5,0.667,1.0,1.5$ and 2.0. The results showed that the aspect ratio affects the growth of smoke fires in the tunnel. The critical velocity increases with the aspect ratio; it was confirmed that high-temperature smoke moved along the ceiling and low-temperature air moved along the lower part of the tunnel.

Moreover, Haukur Ingason et al. (2008) [6] investigated the effect of air velocity on the heat release rate (HRR) and fire characteristics during a fire in the tunnel. The results showed that when increasing the ventilation rate, causing the maximum heat, the release rate increases. The effect of the cross-section on the maximum heat release rates in the tunnel fires was studied by Li et al. (2016) [7]. In that study, they made a model scale tunnel fire with heptane pool fires. For heptane pool fires, decreasing the tunnel height results in an increase of the heat release rate; the heat release rate is about three times that in a free burn test. However, in this research, there is a lack of information about the effect of the aspect ratio on smoke movement and stratification. On the other hand an experimental study on temperature evolution inside the compartment with fire growth and flame ejection through an opening under external wind was considered by $\mathrm{Hu}$, Longhua, et al [8]. They also considered the characterization of buoyant flow stratification and flame extension lengths in the tunnel fires $[9,10]$. Wan, Huaxian, et al. [11] investigated a numerical study on the smoke back-layering length and inlet air velocity of fires in an inclined tunnel under natural ventilation with a vertical shaft. The tunnel inlet air velocity increases when increasing the tunnel slope and HRR. Besides, Ji, Jie, et al. (2019) [12] also performed a numerical investigation on the influence of the length-width ratio of the fire source on the smoke movement and temperature distribution in tunnel fires. Furthermore, many researches relating to fires or fans were carried out in literature [13-37].

Although there are many kinds of research regarding the jet fan operation and efficiency, there is no research relating to the effect of jet fan speed on smoke movement or stratification in tunnel fires. The purpose of this study is to analyze the effect of the jet fan speed, heat release rate and aspect ratio on smoke movement in a tunnel fire. For this purpose, a numerical study of the effect of the jet fan speed, heat release rate and aspect ratio in the tunnel fires has been carried out by using CFD simulation, as shown in Figure 1. The smoke movement, temperature, velocity and visibility are also investigated in this paper to clarify the impact of the jet fan location and velocity in the tunnel.

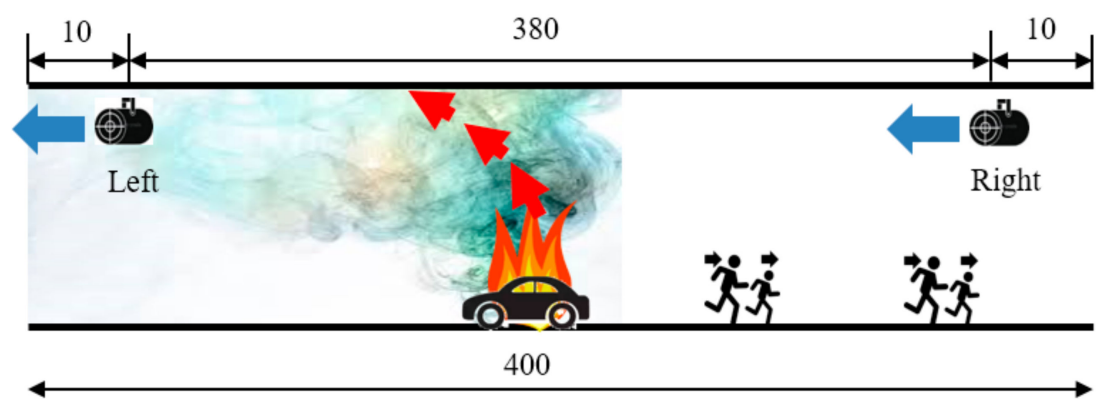

Figure 1. Numerical analysis objective. 


\section{Theoretical Analysis}

\subsection{Jet Fan Speed}

The jet fan centerline velocity can be calculated as follows:

Awbi (2003) [38] and Baturin (1972) [39] provide the equation regarding the centerline velocity and distance for the experiment. The equation includes the centerline velocity, $u_{m}$, the supply velocity, $u_{0}$, distance, $X$, supply diameter of the fan, $d_{0}$, and constant, $a$ (from 0.076 to 0.080 for cylindrical tubes).

With a square duct, Kümmel et al. (2007) [40] provided another equation of jet fan experimental data. It includes the length of the potential core, $x_{0}$, the side length of the square duct, $h$, and constant, $m$ (from 0.12 to 0.2 ).

From these equations, the jet fan centerline velocity can be calculated, as shown in the Figure 2, with the supply velocity at $25 \mathrm{~m} / \mathrm{s}$, and the side length of the square duct at $0.91 \mathrm{~m}$.

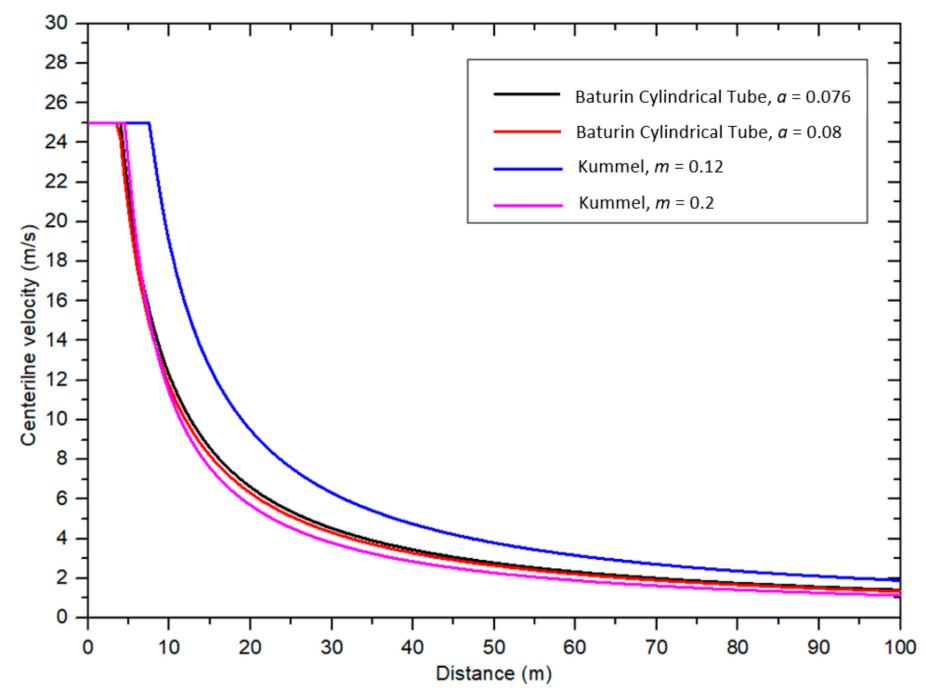

Figure 2. Jet fan centerline velocity.

\subsection{Heat Release Rate}

In this study, the heat release rate was obtained from our experimental study; one car was assumed to be fired in the tunnel. The maximum heat release rate was $3896 \mathrm{~kW}$ at 1551 seconds as shown below Figure 3. Besides, the heat release rate was around $6 \mathrm{MW}$, and $16 \mathrm{MW}$ for two vehicles [41] and truck fires, respectively.

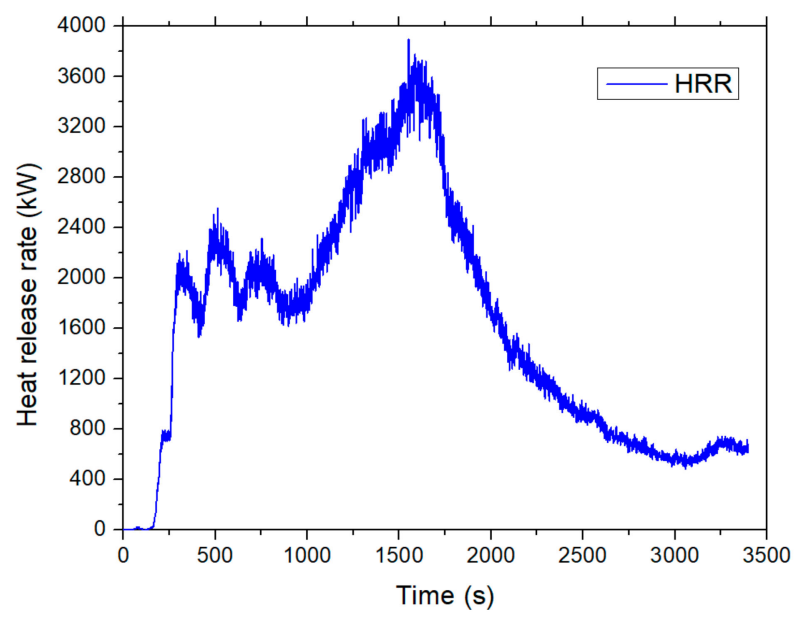

Figure 3. The heat release rate from an experimental study (one vehicle) by Park et al. (2019) [41]. 


\subsection{Smoke Layer Height and Thickness}

There are several methods to determine the smoke layer height and thickness. These include the $N$-percentage rule and integral ratio method. The $N$ percentage rule was developed by Cooper et al. [42]. It is the simplest way to define the smoke layer. This method has been used widely in a much different application, however, it has a limitation. Depending on every region, other $N$ values will be used; this may cause confusion when using $N$ values.

He et al. (1998) [43] proposed another method, which was an integral ratio method. This method divided the temperature profile into two regions, which are the smoke layer and cold air layer. The integral ratio of the smoke layer is $r_{u}$ and the air layer is $r_{l}$. The sum of the integral ratio is $r_{t}$; when $r_{t}$ reaches the minimum value, the interface height can be calculated. As this method is not based on any external reference parameter, it is adopted to obtain a more accurate estimation of the smoke layer thickness in this study.

\section{Numerical Analysis}

\subsection{Computational Domain for Numerical Study}

For this numerical study, the effect of the jet fan speed, heat release rate and aspect ratio on the smoke movement and visibility in tunnel fires would be considered. The geometry of the tunnel and the computation flow domain is presented in Figure 4. The computational domain was extended over the exit and entrance surface, in order to eliminate the influence of the tunnel exit and entrance conditions. Moreover, the computational domain was expanded to the place where the pressure boundary condition was applied. Twenty-four cases have been investigated in this simulation. The parameters of the jet fan velocity, heat release rate and aspect ratio are shown in Table 1.

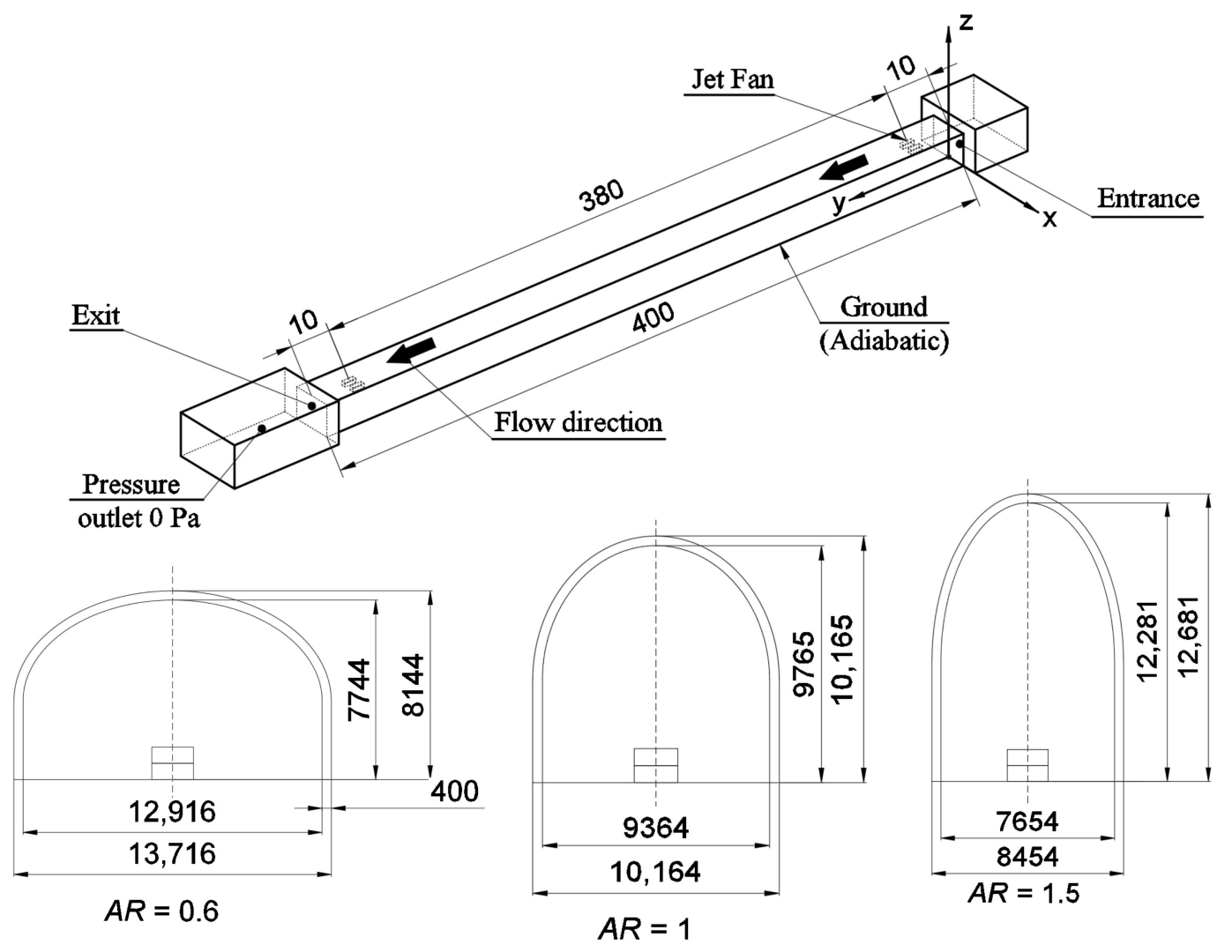

Figure 4. The geometry of the tunnel. 
Table 1. The numerical case studies.

\begin{tabular}{cccc}
\hline Case & HRR $(\mathbf{k W})$ & Jet Fan Velocity $(\mathbf{m} / \mathbf{s})$ & Aspect Ratio \\
\hline 1 & 3896 & 25 & 0.6 \\
2 & 3896 & 18.75 & 0.6 \\
3 & 3896 & 12.5 & 0.6 \\
4 & 3896 & 6.25 & 0.6 \\
5 & 6000 & 25 & 0.6 \\
6 & 6000 & 12.5 & 0.6 \\
7 & 16,000 & 25 & 0.6 \\
8 & 16,000 & 12.5 & 0.6 \\
9 & 3896 & 25 & 1 \\
10 & 3896 & 25 & 1.5 \\
11 & 3896 & 12.5 & 1 \\
12 & 3896 & 12.5 & 1.5 \\
13 & 3896 & 6.25 & 1 \\
14 & 3896 & 6.25 & 1.5 \\
15 & 6000 & 18.75 & 0.6 \\
16 & 6000 & 6.25 & 0.6 \\
17 & 16,000 & 18.75 & 0.6 \\
18 & 16,000 & 6.25 & 0.6 \\
19 & 6000 & 25 & 1 \\
20 & 6000 & 25 & 1.5 \\
21 & 16,000 & 25 & 1 \\
22 & 16,000 & 25 & 1.5 \\
23 & 3896 & 18.75 & 1 \\
24 & 3896 & 18.75 & \\
\hline
\end{tabular}

\subsection{Numerical Method and Boundary Conditions}

\subsubsection{Numerical Method}

The Fire Dynamics Simulator (FDS) is a computational fluid dynamics software developed by the National Institute of Standards and Technology (NIST) of the United States Department of Commerce, in cooperation with the VTT (Valtion Teknillinen Tutkimuskeskus) Technical Research Centre of Finland. This computer program numerically solves large-eddy simulations using Navier-Stokes equations, which are suitable for low-speed flow, thermally driven flow, with an emphasis on smoke and heat transport from the fire to describe the progression of the fire.

The governing equations of FDS can be described as in [44].

\subsubsection{Numerical Condition}

In order to simulate the fire in the tunnel, the initial condition and boundary condition were set up as follows. The ground of the tunnel is adiabatic, the tunnel structure is also adiabatic and the computation domain at the entrance and exit of the tunnel was set up as a zero Pascal pressure gauge.

For the initial condition, the value was set up, as follows in Table 2. The velocity in three directions was $0 \mathrm{~m} / \mathrm{s}$, the temperature was $293.15 \mathrm{~K}$ and the gauge pressure was $0 \mathrm{~Pa}$.

Table 2. The initial conditions.

\begin{tabular}{cc}
\hline Physics & Fluid Flow \\
\hline \multirow{3}{*}{ Cell zone } & Gauge pressure $=0 \mathrm{~Pa}$ \\
& $\mathrm{x}, \mathrm{y}, \mathrm{z}$ velocity $=0 \mathrm{~m} / \mathrm{s}$ \\
& Temperature: $293.15 \mathrm{~K}$ \\
\hline
\end{tabular}




\subsection{Grid Independence Test}

For a numerical study, the independent grid test was performed to get accurate analysis results and the proper size. The number of grids was increased from 915,000 to 2,300,000, and a total of three cases, of a number of grids, were selected as Table 3.

Table 3. The number of grid cells.

\begin{tabular}{cc}
\hline Case Index & Number of Grid Cells \\
\hline Case 1 & $2,300,000$ \\
Case 2 & $1,275,000$ \\
Case 3 & 915,000 \\
\hline
\end{tabular}

From the above Figure 5, when the grid size was $0.1 \mathrm{~m}$, the results showed the best accuracy, so in this case, the grid size of $0.1 \mathrm{~m}$ was used for a nearby fire source, and the grid size of $0.4 \mathrm{~m}$ was used for a location that was far away from the fire source. As it is less critical in this region, the coarse mesh was applied.

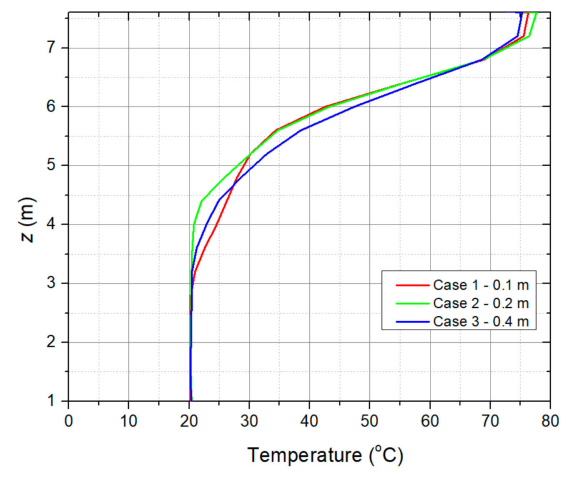

(a)

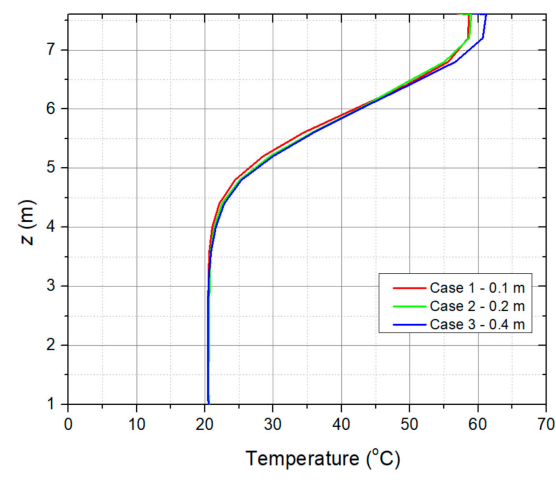

(b)

Figure 5. The vertical temperature distribution: (a) Location $\mathrm{A}(Y=120)$ and $(\mathbf{b})$ Location $\mathrm{B}(Y=300)$.

\section{Results and Discussion}

In this study, a numerical study was conducted to investigate the effect of jet fan speed, heat release rate and aspect ratio on the smoke movement in the tunnel fire for optimizing the ventilation system in the tunnel. For this purpose, the separate effects will be analyzed as follows.

\subsection{Effect of Jet Fan Speed}

To consider the effect of the jet fan speed on smoke movement, the heat release rate and aspect ratio were fixed, as below in Figure 6. The smoke movement is shown through visibility because it is directly related to visibility. 


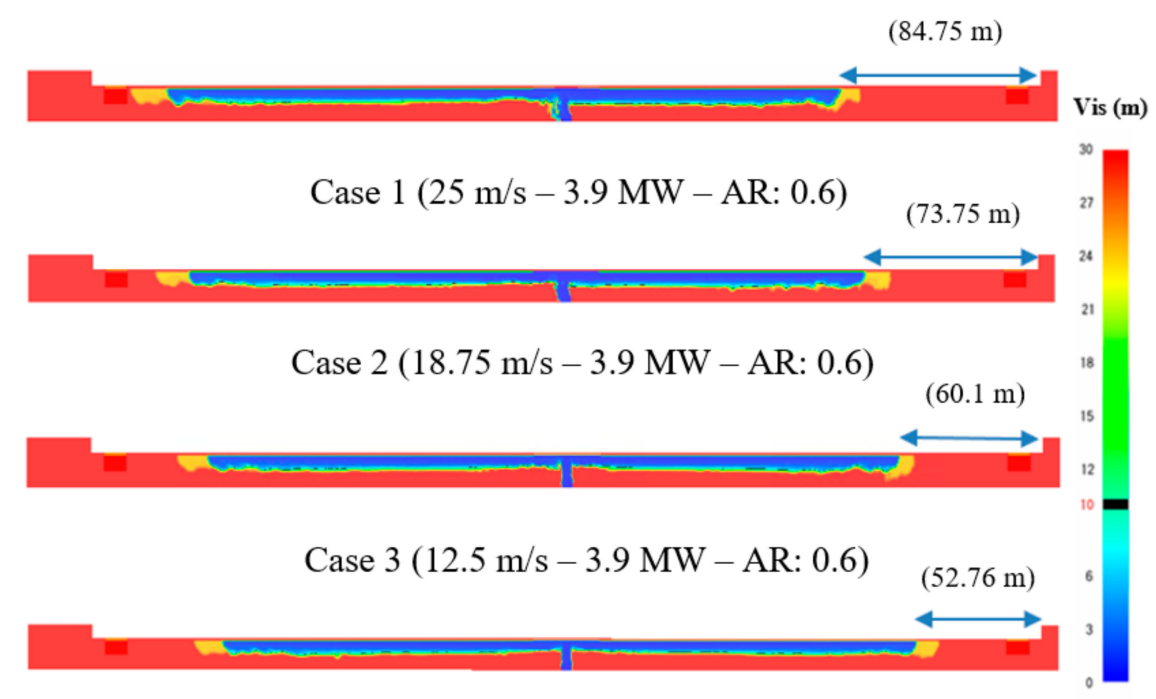

Case $4(6.25 \mathrm{~m} / \mathrm{s}-3.9 \mathrm{MW}-\mathrm{AR}: 0.6)$

Figure 6. Visibility in the tunnel when changing the jet fan speed.

When the jet fan operates with a high velocity, the smoke tends to move to the left side (the exit direction), as there is a significant amount flow rate of the air entrained into the tunnel from the entrance. However, when the jet fan speed is decreased, the smoke tends to move in both directions; and the visibility between the left side and right side had the same distribution.

When changing the jet fan speed, the distances between the smoke and entrance position for case 1, 2, 3 and 4 were $84.75 \mathrm{~m}, 73.75 \mathrm{~m}, 60.1 \mathrm{~m}$ and $52.76 \mathrm{~m}$, respectively. This indicates that the higher the jet fan speed is, the lower the smoke back layer length is. At location $Y=300 \mathrm{~m}$, the smoke layer thicknesses for case 1, 2, 3 and 4 were $2.3 \mathrm{~m}, 2.1 \mathrm{~m}, 2 \mathrm{~m}$ and $1.8 \mathrm{~m}$, respectively. From this result, when decreasing the jet fan speed, the smoke layer thickness decreased. Moreover, the temperature in the tunnel on the tunnel center's plane was also affected by the jet fan speed. In this case, it was confirmed that high-temperature smoke moved along the ceiling and low-temperature air moved along the lower part of the tunnel.

For case 1 in Figure $7 b$, when the height $(z)$ was from 1 to $5.4 \mathrm{~m}$, the velocity was a minus value, indicating that, at this region, the flow (air) moved into the tunnel (moved from the right side to the left side). When the height ( $z$ ) was from 5.4 to $7.6 \mathrm{~m}$, the velocity was a positive value, and in this region, the flow (smoke) from the fire in the tunnel moved outside (moved from the left side to right side). Similarly, from case 2 to case 3 and 4 , the temperature and velocity distribution were also different between these cases. In case 2, when the height was from 1 to $5.4 \mathrm{~m}$, the air moved into the tunnel. When the height was from 5.4 to $7.6 \mathrm{~m}$, the smoke from the fire in the tunnel moved outside. For cases 3 and 4 , when the height was from 1 to $5 \mathrm{~m}$, the air moved into the tunnel. When the height was from 5 to $7.6 \mathrm{~m}$, the smoke from the fire in the tunnel moved outside. The effect of the jet fan speed on flow can be obtained from Figure 7, as well. In the lower part, as the flow was air induced, the absolute velocity value of case 1 (highest speed) was larger than the other cases. However, at the upper part, which was near the ceiling, because all flow was smoke, the absolute velocity value of case 1 (the highest speed) was lower than for the other cases. 


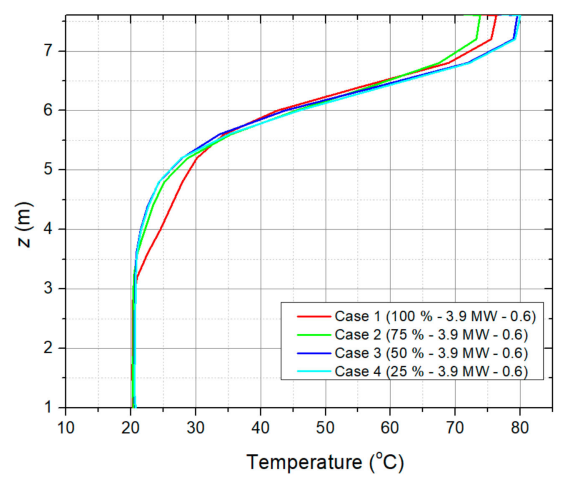

(a)

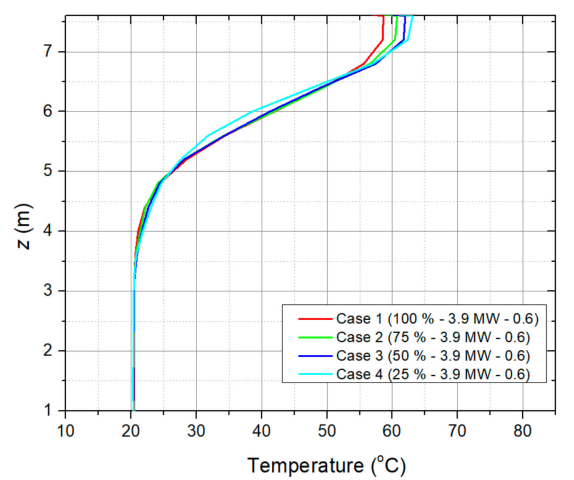

(c)

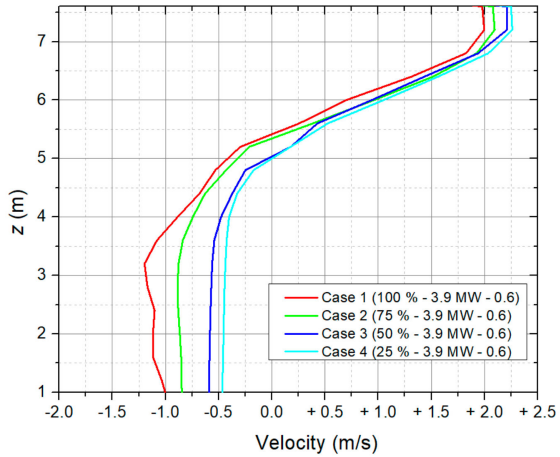

(b)

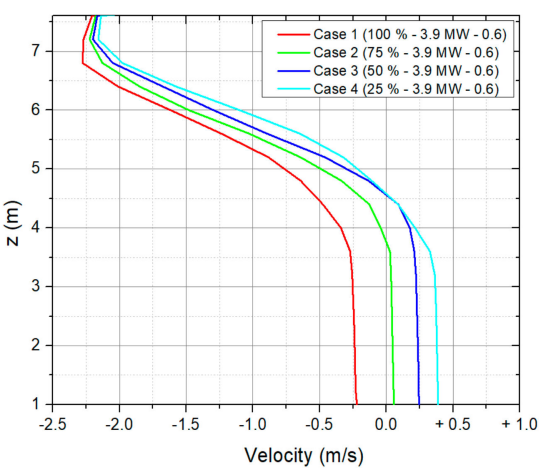

(d)

Figure 7. Temperature and velocity distribution in the tunnel: (a) temperature distribution at $Y=120$; (b) velocity distribution at $Y=120$; (c) temperature distribution at $Y=300$ and (d) velocity distribution at $Y=300$.

\subsection{Effect of Heat Release Rate}

First, the value of the jet fan speed was fixed at $25 \mathrm{~m} / \mathrm{s}$, the aspect ratio was 0.6 and the heat release rate was changed. The smoke movement in these cases on the tunnel center's plane is shown in Figure 8 . In case 1 , the velocity of the jet fan was $25 \mathrm{~m} / \mathrm{s}(100 \%)$, and the smoke movement was totally different between the left side and right side. The smoke tended to move to the left side (exit direction). As, in this case, the jet fan operated with a high velocity, there was a significant amount of flow rate of the air coming inside the tunnel from the entrance. Therefore, it pushed the smoke to move to the exit direction. Moreover, the heat release rate was 3.9 MW, thus the amount of smoke was not high. However, when increasing the heat release rate, the amount of smoke was more significant. In case 7 , with a $16 \mathrm{MW}$ heat release rate, the smoke moved in both directions. In the region near the entrance, due to the effect of a jet fan, stratification occurred. The visibility was lower when compared with other cases, as a result, and it was difficult for evacuation. 


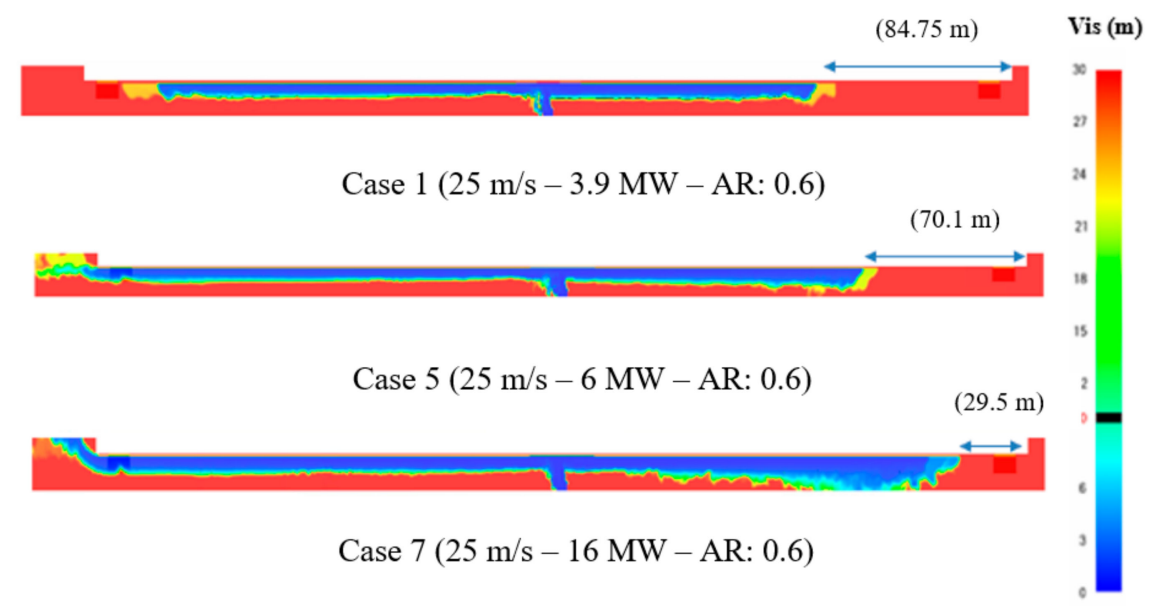

Figure 8. Visibility in the tunnel fire when changing the HRR.

Moreover, when changing the heat release rate, the length of the smoke back layer was quite different. The distances between the smoke and entrance position for case 1 , case 5 and case 7 were $84.75 \mathrm{~m}, 70.1 \mathrm{~m}$ and $29.5 \mathrm{~m}$, respectively. This indicates that the smoke back layer length was affected by the heat release rate. With the higher heat release rate, the smoke back layer length was higher. Additionally, at location $Y=300 \mathrm{~m}$, the smoke layer thicknesses for case 1,5 and 7 were $2.3 \mathrm{~m}, 2.4 \mathrm{~m}$ and $2.7 \mathrm{~m}$, respectively. Thus, the larger the heat release rate is, the thicker the smoke layer is.

The velocity vector at the center plane for cases 1, 5 and 7 are shown in Figure 9. In case 7, at the distance $29.5 \mathrm{~m}$ from the entrance, the smoke and air from the jet fan were mixed. The velocity vector of the air from jet fan tended to move down. The stratification occurred in this region.

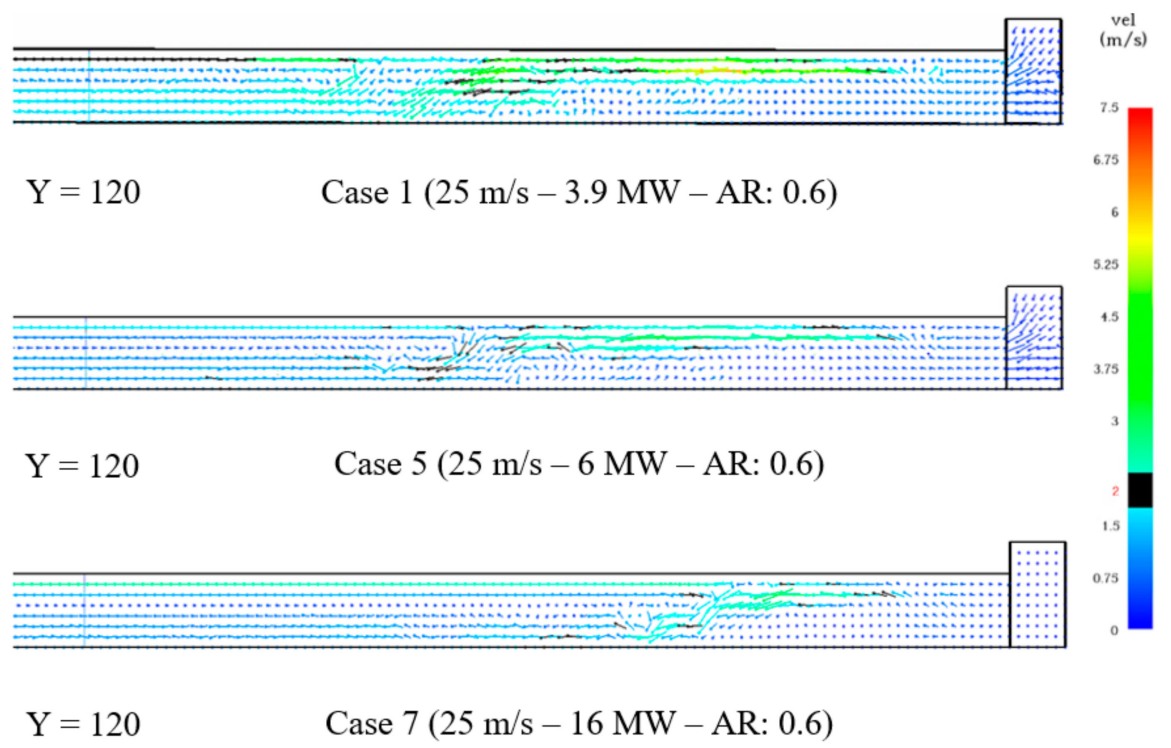

Figure 9. Velocity vector in the tunnel fire when changing the HRR.

In Figure 10a at the upper part, the larger the heat release rate was, the higher the temperature was. Besides, the velocity was also larger when the heat release rate was larger. In the lower part, because all flow was air so that the absolute velocity value of case 1 (lowest heat release rate) was lower than other cases. When the heat release rate was low, it means the amount of air needed for fire combustion was also lower, so that the air coming inside the tunnel was low (case 1), and the smoke movement was quite weak when compared with other cases. However, with a higher heat release rate, the amount of air needed for the combustion process was larger and the smoke generated by the combustion process was also larger, so the velocity value, in this case, was greater than in other cases. 


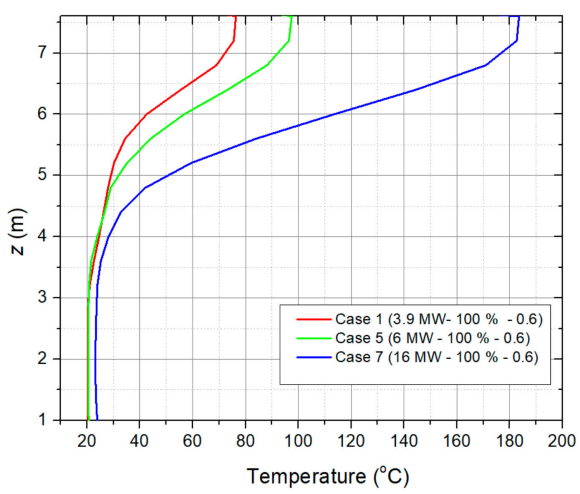

(a)

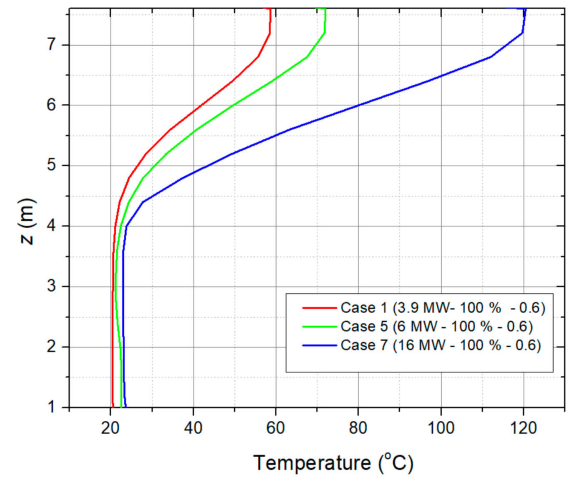

(c)

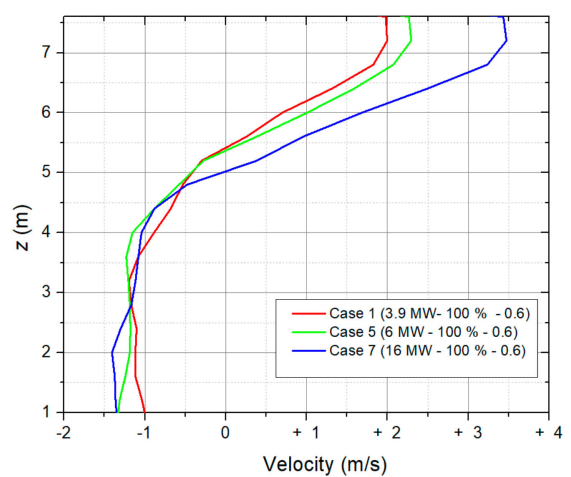

(b)

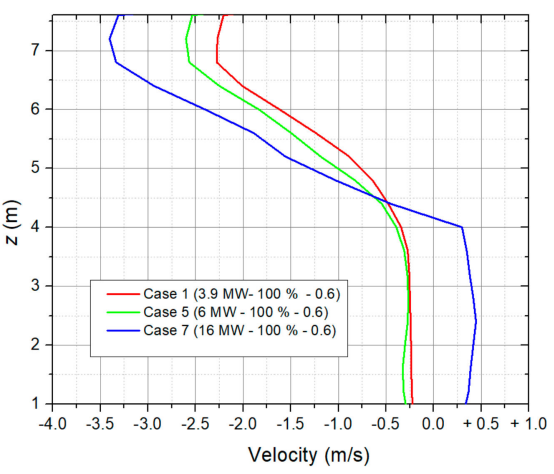

(d)

Figure 10. Temperature and velocity distribution in the tunnel: (a) temperature distribution at $Y=120$; (b) velocity distribution at $Y=120$; (c) temperature distribution at $Y=300$ and (d) velocity distribution at $Y=300$.

\subsection{Effect of Aspect Ratio}

In order to analyze the effect of aspect ratio on smoke movement, the numerical study was investigated by fixing the value of the jet fan speed and the heat release rate, and the aspect ratio was changed from 0.6 to 1 and 1.5 .

First, the value of the jet fan speed was $25 \mathrm{~m} / \mathrm{s}$, and the heat release rate was $3.9 \mathrm{MW}$, and the aspect ratio was changed. The smoke movement in these cases was shown in the figures below, through visibility.

For case 1 in Figure 11, the velocity of the jet fan was $25 \mathrm{~m} / \mathrm{s}$, and the smoke movement was completely different between the left side and right side. In this case, the smoke tended to move to the left side (exit direction). As, in case 1, the jet fan operated with a high velocity, thus there was a tremendous flow rate of the air-entrained inside the tunnel. Therefore, it pushed the smoke to move to the exit direction. The heat release rate was 3.9 MW; thus, the amount of smoke was not high. However, when increasing the aspect ratio, the smoke could move outside quickly. In the region near the entrance, due to the effect of the jet fan, stratification occurred with the largest aspect ratio (case 10). The visibility was lower when compared with other cases, and as a result, it was difficult for the evacuation to proceed. 


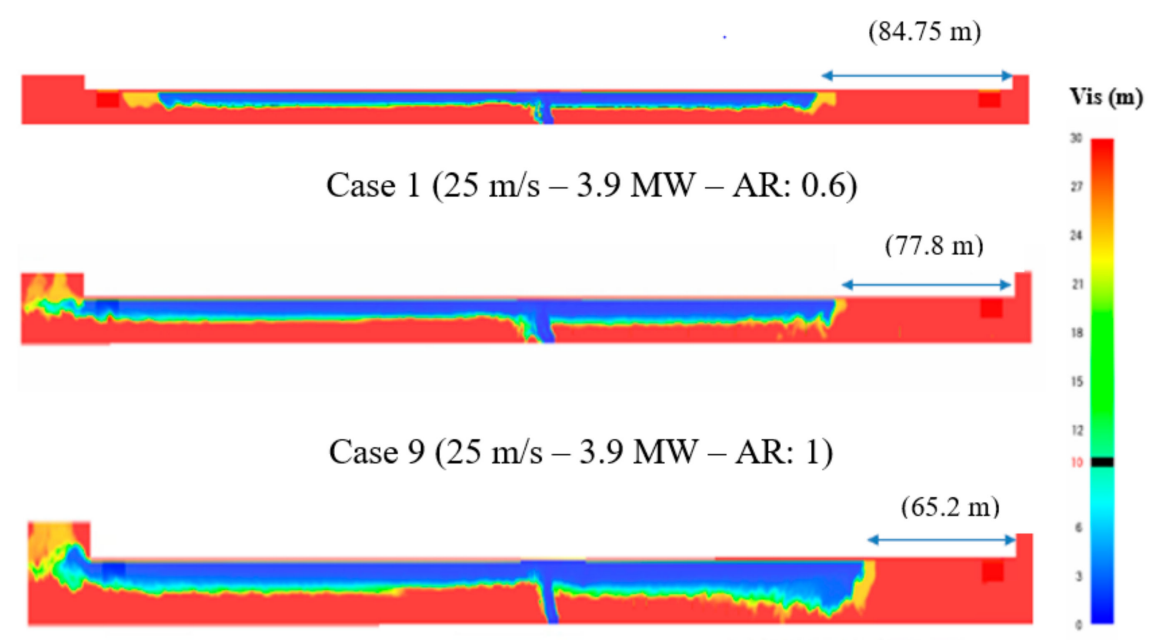

Case $10(25 \mathrm{~m} / \mathrm{s}-3.9 \mathrm{MW}-\mathrm{AR}: 1.5)$

Figure 11. Visibility in the tunnel fire when changing the aspect ratio.

Furthermore, when changing the aspect ratio, the distance between the smoke and entrance position from case 1 , case 9 and case 10 were $84.75 \mathrm{~m}, 77.8 \mathrm{~m}$ and $65.2 \mathrm{~m}$, respectively. This indicates that the smoke back layer length was affected by the aspect ratio. With the high aspect ratio, the smoke back layer length was higher.

In Figure 12a, at the upper part, the lower the aspect ratio was, the larger the temperature was. When the aspect ratio increased, the velocity increased. This is because the width of the tunnel decreased when increasing the aspect ratio. In the lower part, as all flow was air, the absolute velocity value of case 1 (lowest aspect ratio) was lower than in other cases.

As shown in the previous sections, when increasing the heat release rate, the smoke layer length was also increased. The reason for this is that when the heat release rate of fire was larger, the amount of smoke generated was also higher. This caused the smoke to move quickly, so the smoke layer length was also increased. In contrast, when the jet fan speed was increased, the smoke layer length was decreased.

The result shows that when the aspect ratio increased, the smoke back layer length also increased. When the aspect ratio was larger, this indicates that the height of the tunnel was higher. For that reason, the smoke was affected by buoyancy force, leading to the smoke movement being larger, and the smoke layer length being longer. The higher the jet fan speed was, the shorter the smoke back layer length was.

Furthermore, when changing both the heat release rate and aspect ratio, with a higher heat release rate or aspect ratio, the smoke layer length was also larger. This was in agreement with the above conclusion in previous figures.

In the tunnel fires, the ceiling jet velocity is calculated by the following equation [45]

$$
\left(\frac{V_{\max }}{\sqrt{g H}}\right) / Q_{c}^{* 1 / 3}=0,5812\left(\frac{l_{b}}{H}\right)^{-1 / 3} \exp \left[-1.567 . S t \cdot \frac{x}{H}\left(\frac{l_{b}}{H}\right)^{1 / 3}\right]
$$

where $V_{\max }$ is maximum ceiling jet velocity, $H$ is tunnel height, $Q_{c}{ }^{*}$ dimensionless heat release rate $=$ $Q_{c} /\left(\rho_{\infty} C_{p} T_{\infty} g^{1 / 2} H^{5 / 2}\right), l_{b}$ is half-width of tunnel $=W / 2$, St is Stanton number and $x$ is the horizontal distance from the center of fire source $(\mathrm{m})$. 


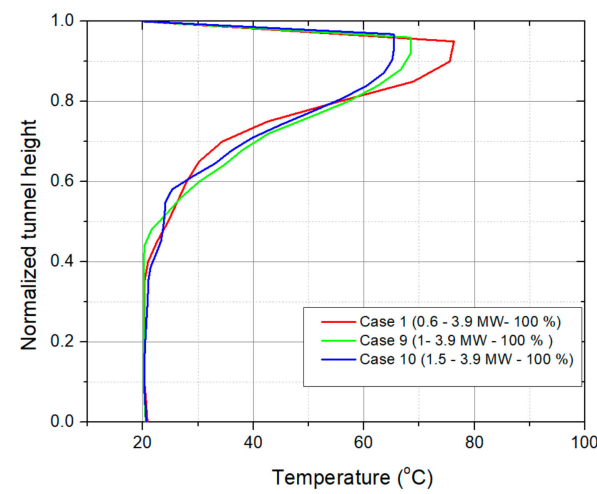

(a)

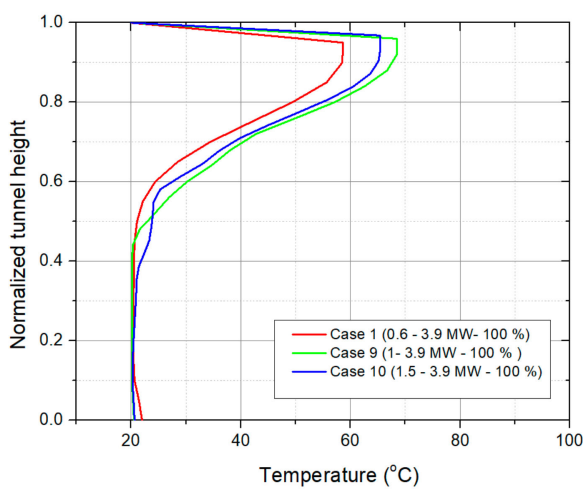

(c)

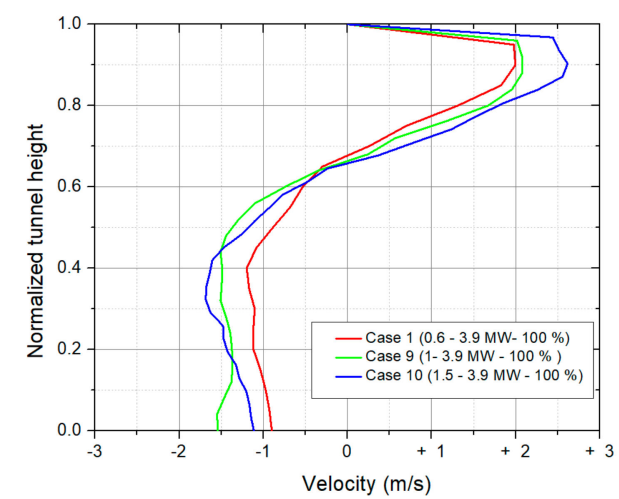

(b)

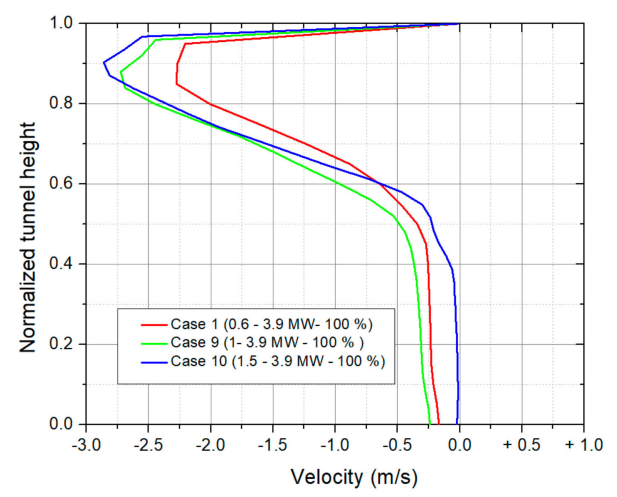

(d)

Figure 12. Temperature and velocity distribution in the tunnel: (a) temperature distribution at $Y=120$; (b) velocity distribution at $Y=120$; (c) temperature distribution at $Y=300$ and (d) velocity distribution at $Y=300$.

Based on the above equation, the following equation can be derived.

$$
V_{\max }=\sqrt{g \cdot A R \cdot 2 l_{b}} \cdot Q_{c}^{* 1 / 3} \cdot 0,5812\left(\frac{1}{2 \cdot A R}\right)^{-1 / 3} \exp \left[-1.567 \cdot S t \cdot \frac{x}{A R \cdot l_{b}}\left(\frac{1}{2 \cdot A R}\right)^{1 / 3}\right]
$$

where $A R$ is aspect ratio $=H / 2 l_{b}$

On the other hand, the jet fan velocity can be applied by the equation as in Section 2.1.

$$
U_{m}=\frac{0.48 U_{0}}{\left(a X / d_{0}+0.145\right)}
$$

In order to avoid the smoke back layer length, the velocity of the jet fan at distance $X\left(U_{m}\right)$ has to be larger than the ceiling jet velocity $\left(V_{\max }\right)$. So, that the following equation can be derived from Equations (2) and (3)

$$
U_{0}>\frac{\left(a(L-x) / d_{0}+0.145\right)}{0.48} \cdot \sqrt{g \cdot A R \cdot 2 l_{b}} \cdot Q_{c}^{* 1 / 3} \cdot 0,5812\left(\frac{1}{2 \cdot A R}\right)^{-1 / 3} \exp \left[-1.567 \cdot S t \cdot \frac{x}{A R \cdot l_{b}}\left(\frac{1}{2 \cdot A R}\right)^{1 / 3}\right]
$$

where $L$ is the distance from the center of fire source to a jet fan location.

Based on Equation (4), as the left term and right term are equal, it means that the smoke movement keeps stable. From that point, the distance $x$ is the place in which the ceiling jet velocity and jet fan velocity are equal. So, $x$ (smoke back layer length) can be derived from Equation (4). The results of Equation (4) are shown in Figures 13 and 14. 


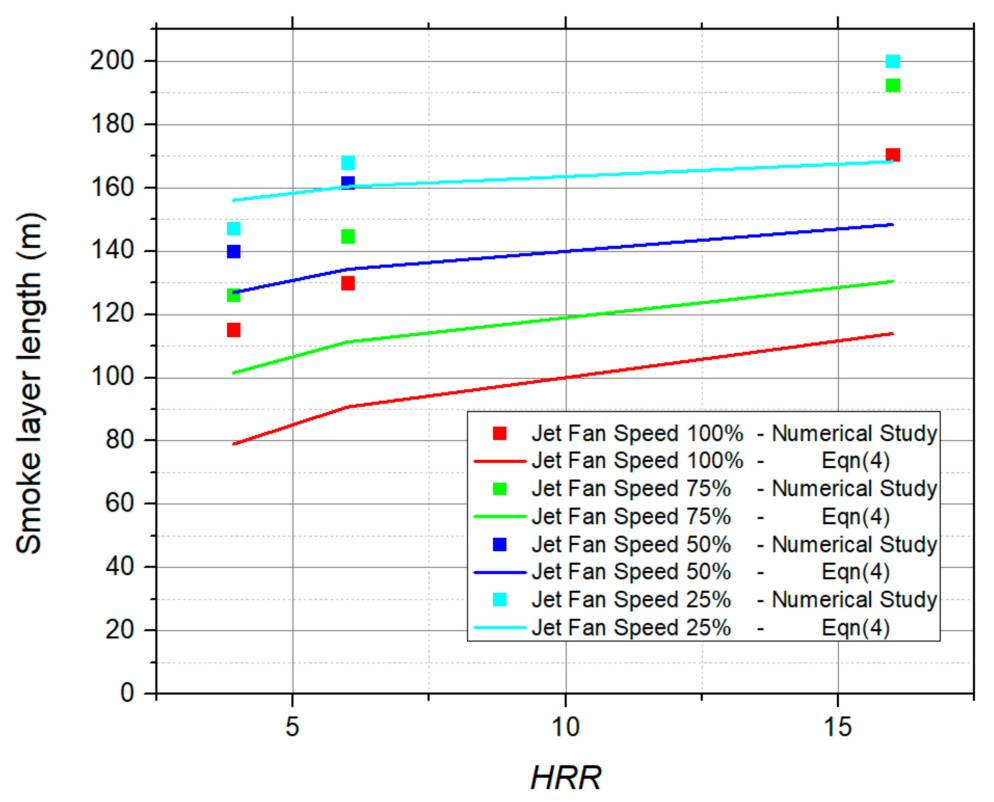

Figure 13. Smoke back layer length in the relationship between $H R R$ and jet fan speed.

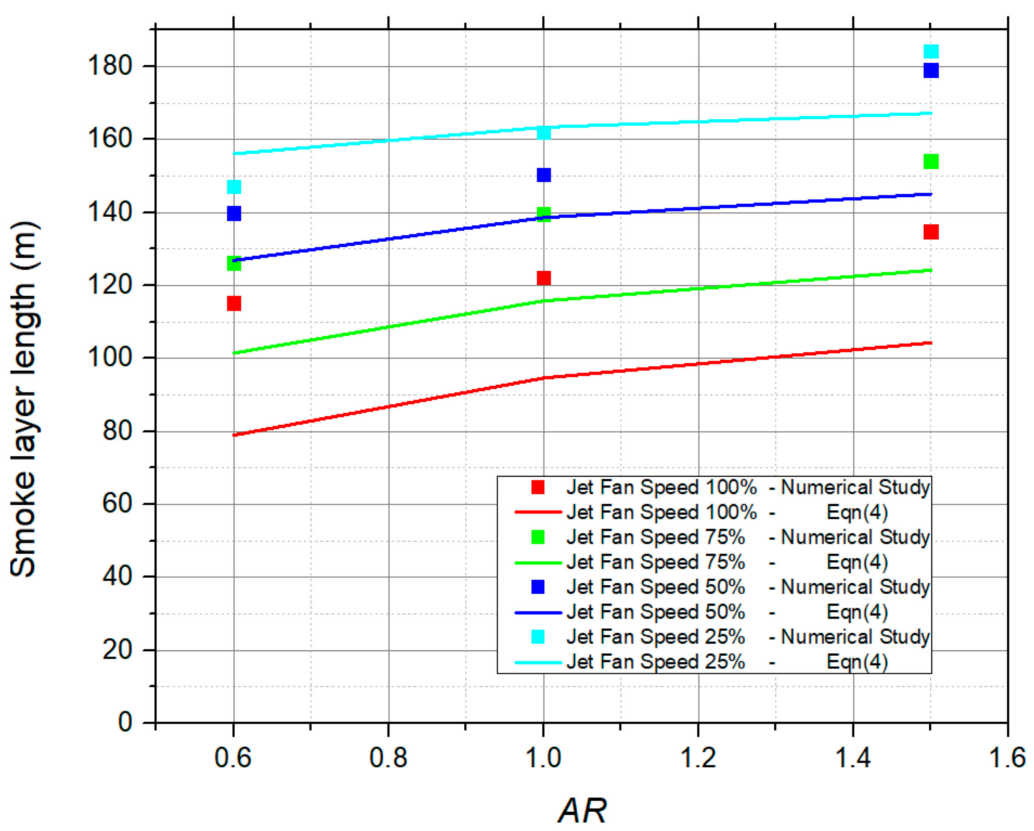

Figure 14. Smoke back layer length in relationship between $A R$ and jet fan speed.

The smoke back layer length in the correlation between the heat release rate and jet fan speed is shown in Figure 13, the dots represent the results obtained by numerical study, and the line is the results from Equation (4). The figure shows that when increasing the heat release rate, the smoke layer length was also increased for both the numerical study and Equation (4). The reason is that when the heat release rate of fire was larger, the amount of smoke generated was also higher, it tended to cause the smoke to move quickly, the result was that the smoke layer length was also increased. In contrast, when the jet fan speed increased, the smoke layer length decreased, as this depends on a large amount of air that has been transported at high speed. Similarly, in Figure 14, when increasing the aspect ratio, the smoke layer length was also increased for both the numerical study and Equation (4), because when the aspect ratio was larger, it means the height of the tunnel was higher. For that reason, the smoke affected by buoyancy force led to the smoke movement being larger and the smoke layer length being longer, obviously. In this figure, the effect of the jet fan speed on the smoke layer length was also 
the same as the previous figure. The higher the jet fan speed was, the shorter the smoke layer length was. In Equation (4), there are some coefficients representing the temperature and velocity attenuation. Besides, because the two jet fans operated, it caused discrepancy in the coefficient. For that reason, the results had a little bit of error between the equation and numerical study. The future work will be investigated to find out that correction.

\section{Conclusions}

In this study, the numerical study of the effect of jet fan speed, heat release rate and aspect ratio on smoke movement in tunnel fires was investigated. The effect of the jet fan speed, heat release rate and aspect ratio on smoke movement and visibility and stratification in tunnel fires were drawn as follows:

The lower the jet fan speed is, the longer the smoke back-layering is, as this depends on a small amount of air that has been transported at low speed. The smoke tends to spread in both directions.

When changing the jet fan's speed to a high velocity, the smoke tends to move to the exit direction, because the flow rate of air that enters the tunnel is higher, thus, the smoke can quickly move outside. However, smoke stratification also occurs and the smoke and air are mixed. This reduces visibility, and it is difficult for people to evacuate.

The lower the heat release is, the lower the smoke back-layering is. With a higher heat release rate, the smoke tends to move far away from the fires when compared with other cases. With a high heat release rate, the stratification of smoke occurs quite strongly, as it is affected by both the heat release rate and jet fan. This causes difficulty for people evacuating; thus, it is important to optimize the jet fan speed to avoid stratification occurring in the tunnel.

The higher the aspect ratio is, the higher the smoke back-layering is. With a higher aspect ratio, the smoke can move outside quickly. On the other hand, stratification also occurs strongly, as compared with other cases.

The jet fan velocity has been investigated to avoid the smoke back layering as Equation (4).

For these reasons, it is necessary to consider the effects of jet fan speed, heat release rate and aspect ratio when designing mechanical ventilation systems in tunnels.

Author Contributions: Writing—original draft preparation, H.T.K. and Y.M.L.; formal analysis, H.T.K. and Y.M.L. and J.T.K.; writing - review and editing, H.S.R. All authors have read and agreed to the published version of the manuscript.

Funding: This research was funded by NRF, grant number 2019R1F1A1061741 and Chung-Ang University Young Scientist Scholarship (CAYSS) Program 2018.

Acknowledgments: This research was supported by Chung-Ang University Young Scientist Scholarship (CAYSS) Program.

Conflicts of Interest: The authors declare no conflict of interest.

\section{References}

1. Viegas, J.C. The use of impulse ventilation for smoke control in underground car parks. Tunn. Undergr. Space Technol. 2010, 25, 42-53. [CrossRef]

2. Vd Giesen, B.J.M.; Penders, S.H.A.; Loomans, M.G.L.C.; Rutten, P.G.S.; Hensen, J.L.M. Modelling and simulation of a jet fan for controlled airflow in large enclosures. Environ. Model. Softw. 2011, 26, 191-200. [CrossRef]

3. Pei, G.; Pan, J. Numerical study on different series modes of the jet fan in a longitudinal tunnel ventilation system. Math. Probl. Eng. 2014, 2014, 194125. [CrossRef]

4. Beyer, M.; Sturm, P.J.; Saurwein, M.; Bacher, M. Evaluation of Jet Fan Performance in Tunnels. In Proceedings of the 8th International Conference Tunnel Safety and Ventilation, Graz, Austria, 25-26 April 2016.

5. Lee, S.R.; Ryou, H.S. An experimental study of the effect of the aspect ratio on the critical velocity in longitudinal ventilation tunnel fires. J. Fire Sci. 2005, 23, 119-138. [CrossRef]

6. Lönnermark, A.; Ingason, $\mathrm{H}$. The effect of air velocity on heat release rate and fire development during fires in tunnels. Fire Saf. Sci. 2008, 9, 701-712. [CrossRef] 
7. Li, Y.Z.; Fan, C.G.; Ingason, H.; Lönnermark, A.; Ji, J. Effect of cross section and ventilation on heat release rates in tunnel fires. Tunn. Undergr. Space Technol. 2016, 51, 414-423. [CrossRef]

8. Hu, L.; Ren, F.; Hu, K.; Tang, F.; Lu, K. An experimental study on temperature evolution inside compartment with fire growth and flame ejection through an opening under external wind. Proc. Combust. Inst. 2017, 36, 2955-2962. [CrossRef]

9. Tang, F.; Li, L.J.; Dong, M.S.; Wang, Q.; Mei, F.Z.; Hu, L.H. Characterization of buoyant flow stratification behaviors by Richardson (Froude) number in a tunnel fire with complex combination of longitudinal ventilation and ceiling extraction. Appl. Therm. Eng. 2017, 110, 1021-1028. [CrossRef]

10. Qiu, A.; Hu, L.; Chen, L.; Carvel, R.O. Flame extension lengths beneath a confined ceiling induced by fire in a channel with longitudinal air flow. Fire Saf. J. 2018, 97, 29-43. [CrossRef]

11. Wan, H.; Gao, Z.; Han, J.; Ji, J.; Ye, M.; Zhang, Y. A numerical study on smoke back-layering length and inlet air velocity of fires in an inclined tunnel under natural ventilation with a vertical shaft. Int. J. Therm. Sci. 2019, 138, 293-303. [CrossRef]

12. Ji, J.; Tan, T.; Gao, Z.; Wan, H.; Zhu, J.; Ding, L. Numerical investigation on the influence of length-width ratio of fire source on the smoke movement and temperature distribution in tunnel fires. Fire Technol. 2019, 55, 963-979. [CrossRef]

13. Khattri, S.K.; Log, T.; Kraaijeveld, A. Tunnel Fire Dynamics as a Function of Longitudinal Ventilation Air Oxygen Content. Sustainability 2019, 11, 203. [CrossRef]

14. Khattri, S.K. From small-scale tunnel fire simulations to predicting fire dynamics in realistic tunnels. Tunn. Undergr. Space Technol. 2017, 61, 198-204. [CrossRef]

15. Ji, J.; Guo, F.; Gao, Z.; Zhu, J. Effects of ambient pressure on transport characteristics of thermal-driven smoke flow in a tunnel. Int. J. Therm. Sci. 2018, 125, 210-217. [CrossRef]

16. Gao, Z.; Jie, J.; Wan, H.; Zhu, J.; Sun, J. Experimental investigation on transverse ceiling flame length and temperature distribution of sidewall confined tunnel fire. Fire Saf. J. 2017, 91, 371-379. [CrossRef]

17. Carvel, R.O.; Beard, A.N.; Jowitt, P.W.; Drysdale, D.D. Fire size and fire spread in tunnels with longitudinal ventilation systems. J. Fire Sci. 2005, 23, 485-518. [CrossRef]

18. Kim, J.H.; Kim, J.H.; Kim, K.Y.; Yoon, J.Y.; Yang, S.H.; Choi, Y.S. High-efficiency design of a tunnel ventilation jet fan through numerical optimization techniques. J. Mech. Sci. Technol. 2012, 26, 1793-1800. [CrossRef]

19. Lee, S.R.; Ryou, H.S. A numerical study on smoke movement in longitudinal ventilation tunnel fires for different aspect ratio. Build. Environ. 2006, 41, 719-725. [CrossRef]

20. Janssens, M.; Tran, H.C. Data reduction of room tests for zone model validation. J. Fire Sci. 1992, 10, 528-555. [CrossRef]

21. Muckett, M.; Furness, A. Introduction to Fire Safety Management; Routledge: Abingdon upon Thames, UK, 2007.

22. Šekularac, M.B. Experimental determination of tunnel ventilation axial ducted fan performance. Therm. Sci. 2016, 20, 209-221. [CrossRef]

23. Dahm, W.J.A.; Dimotakis, P.E. Measurements of entrainment and mixing in turbulent jets. AIAA J. 1987, 25, 1216-1223. [CrossRef]

24. Lönnermark, A.; Ingason, H. Fire Spread in Large Industrial Premises and Warehouse; SP Swedish National Testing and Research Institute: Borås, Sweden, 2005.

25. Grant, G.; Drysdale, D. Numerical modelling of early flame spread in warehouse fires. Fire Saf. J. 1995, 24, 247-278. [CrossRef]

26. Drysdale, D. An Introduction to Fire Dynamics; John Wiley and Sons: Hoboken, NJ, USA, 1986.

27. Jun, Y.J. Deduction of Key Items and Task Improvement for Quality Test of Curtain Wall. Master's Thesis, University of Seoul, Seoul, Korea, 2012.

28. Kweon, O.S.; Yoo, Y.H.; Kim, H.Y.; Kim, J.H. Real Scale Experiment for Assessing Fire Model of Office Compartment. J. Korean Soc. Hazard Mitig. 2012, 12, 61-65. [CrossRef]

29. Lee, J.S.; Yim, H.C.; Kim, H.J.; Kim, H.Y.; Cho, B.H. An Experimental Study on the Evaluation of Fire Resistance Performance of Curtain-Wall. J. Archit. Inst. Korea 2011, 27, 141-148.

30. Mowrer, F.W. Window Breakage Induced by Exterior Fires. In Proceedings of the Second International Conference on Fire Research and Engineering (ICFRE2), Maui, HI, USA, 3-9 May 1998; pp. 404-415.

31. Pagni, P.J.; Joshi, A.A. Glass Breaking in Fires. Fire Saf. Sci. 1991, 3, 791-802. [CrossRef]

32. Rahkonen, O.K. Breaking of Window Glass Close to Fire. Fire Mater. 1988, 12, 60-69. 
33. Roh, J.S.; Yang, S.S.; Ryou, H.S. Tunnel fires: Experiments on Critical Velocity and Burning Rate in Pool Fire During Longitudinal Ventilation. J. Fire Sci. 2005, 25, 161-176. [CrossRef]

34. Shields, T.J.; Silcock, G.W.H.; Flood, M. Performance of a Single Glazing Assembly Exposed to a fire in the Centre of and Enclosure. Fire Mater. 2002, 26, 51-75. [CrossRef]

35. Shields, T.J.; Silcock, G.W.H.; Flood, M. Behavior of Double Glazing in Corner Fires. Fire Technol. 2005, 41, 37-65. [CrossRef]

36. Wu, C.W.; Lin, T.H.; Lei, M.Y.; Chung, T.H.; Huang, C.C.; Chiang, W.T. Fire Resistance Tests of a Glass Pane with Down-flowing Water Film. J. Chin. Inst. Eng. 2008, 31, 737-744. [CrossRef]

37. Xie, Q.; Zhang, H.; Wan, Y.; Zhan, Q.; Cheng, X. Full-scale experimental study on crack and fallout of toughened glass with different thicknesses. Fire Mater. 2008, 32, 293-306. [CrossRef]

38. Awbi, H.B. Ventilation of Buildings, 2nd ed.; Spon Press: London, UK, 2003.

39. Baturin, V.V. Fundamentals of Industrial Ventilation; Pergamon: Oxford, UK, 1972.

40. Kümmel, W. Technische Strömungsmechanik, 3rd ed.; Technical Report; Teubner, B.G., Ed.; Teubner: Wiesbaden, Germany, 2007; p. 25.

41. Park, Y.; Ryu, J.; Ryou, H.S. Experimental Study on the Fire-Spreading Characteristics and Heat Release Rates of Burning Vehicles Using a Large-Scale Calorimeter. Energies 2019, 12, 1465. [CrossRef]

42. Cooper, L.Y.; Harkleroad, M.; Quintiere, J.; Rinkinen, W. An experimental study of upper hot layer stratification in full-scale multiroom fire scenarios. J. Heat Transfer 1982, 104, 741-749. [CrossRef]

43. He, Y.; Fernando, A.; Luo, M. Determination of interface height from measured parameter profile in enclosure fire experiment. Fire Saf. J. 1998, 31, 19-38. [CrossRef]

44. Kevin, M.; Simo, H.; Jason, F. Fire dynamics simulator (version 5) technical reference guide. NIST Spec. Publ. 2007, 1018, 5 .

45. Oka, Y.; Oka, H. Velocity and temperature attenuation of a ceiling-jet along a horizontal tunnel with a flat ceiling and natural ventilation. Tunn. Undergr. Space Technol. 2016, 56, 79-89. [CrossRef]

(C) 2020 by the authors. Licensee MDPI, Basel, Switzerland. This article is an open access article distributed under the terms and conditions of the Creative Commons Attribution (CC BY) license (http://creativecommons.org/licenses/by/4.0/). 